bronchioles being pigmented at their bifurcation, producing a peculiar appearance, as if a big $V$ was stamped or painted in the middle of each lobule. The lower portion of the lung was in an earlier stage of disease-a hard congestion of a patchy character being presented to view, resembling an infective pneumonia. The right lung was completely adherent except at a space at the lower anterior portion, where there was a small collection of recently formed pus. The condition of the lung was similar to that of the left, but the disease had progressed farther, and the caseiform material had broken down, leaving a cavity of the size of a Maltese orange. At first I could find no tubercle, but on careful search two racemose groups of recent tubercle were found below and in close proximity to the cavity. The spleen was pale, small, soft, and diffluent, and resembled the pyæmic
spleen. The lungs were carefully examined microscopically; and, naturally anxious to have my views corroborated, I submitted sections to Dr. Klein, who was good enough to examine them, and expressed the opinion that they indicated an infective pneumonia.

I must remark with regard to this case that I have never come across a case of ordinary phthisis which at all resembled it, and although I have been on the alert for indications regarding the nature of the clinical symptoms which appear to mark cases of acute infection, I have not had an opportunity of investigating any other case of the kind. If further observation should corroborate this evidence, it would, I think, lead to the conclusion that phthisis in its power of communicating disease must be looked upon not as a zymotic disease capable of sowing itself, and reproducing the same form of disease, with identical symptoms and signs, but rather as an ulcerative process capable of giving rise to pyæmia. This view of the infection of phthisis would induce less terror than the notion that it was a contagious disease in the generally accepted view of the term, and prevention might be expected from simple measures of hygiene, especially free ventilation of the patient's room. Such means might reduce the risk of infection to a minimum without preventing that assiduous care and attention which alleviates and soothes the last days of the dying invalid, and the devoted wife need not fall a victim to her duty and ministering care.

It may perhaps be necessary for me to state that cases come under observation with a history of possible infection of which the symptoms are less marked and intense, and in which the pulmonary disease is not distinctive enough to constitute a diagnosis. How far such cases may be classed with those acute and intense forms of disease which I have attempted to describe, and how nearly they may resemble ordinary phthisis, is a matter which will have to be decided by the features of each individual case. I wish especially to guard against the supposition that in all cases of infection the form and progress of the disease must assume the same strikingly marked features which appear to characterise the acute and intense form of the infective disease.

\section{REMARKS ON STRICTURE OF THE URETHRA IN CONNEXION WITH INTERNAL URETHROTOMY.}

\section{BY SURGEON-MAJOR T. J. MCGANN, I.M.D.,} CIVIL SURGEON, MYSORE.

THE gist of my communication lies in the fact that in several bad cases of stricture which have come under my care recently, $I$ have at once, without any previous efforts to treat them by gradual dilatation, resorted to internal urethrotomy, and with very satisfactory results so far. The instrument I have used has been that of Mr. Teevan, which was described by him in March, 1878.

The natives of India are, as a rule, very reluctant to seek treatment for stricture, and will go on without such as long as they can pass urine, even in a very small stream, or squeeze it out drop by drop, and so relieve themselves for the time; and hence cases of extravasation, with sloughing of scrotum and perineum, are not uncommon, and less so still are bad strictures. It is, therefore, with the worst class of cases that one has, as a rule, to deal with, and even these rarely come to hospital until actual retention has occurred, with probably an over-distended bladuer and rupture of the urethra imminent, so that prompt measures are demanded. In Indian hospitals the supply of catheters and bougies is limited, and as they rapidly deteriorate from climatic causes, and become inefficient after very little use, and as it is the small sizes which are most frequently used, surgeons often find themselves with notling but large ones in hand. I have, there. fore, on occasions felt anything but pleasure at being called on to treat an urgent case, with perhaps a bladder distended to the umbilicus, a tight tortuous stricture, impassable to any instrument within my reach or obtainable in a reason. able time, aggravated, perhaps, by an indurated distorted condition of perineum. Under circumstances such as those enumerated, and with no very small instruments available, it will be readily conceived that puncture of the bladder has had frequently to be resorted to to relieve present urgent symptoms, and as a preliminary to other treatment; and although I have hitherto found puncture per rectum a perfectly safe operation, it will be admitted that it is undesirable to have recourse to it as a routine measure in every bad case of stricture that comes under treatment, albeit it gives time and admits of good results being achieved afterwards.

About a year ago I procured, through my friend $\mathrm{Dr}$. Macgrath of Bayswater, Mr. Teevan's urethrotome, for a bad stricture complicated with numerous fistulæ, which, after much trouble, I dilated up to No. 11, English, but which contracted again very rapidly, notwithstanding the occasional introduction of the full rigid instrument by the patient, and two of the openings never completely healed. After the free use of the urethrotome in this case the fistulous openings healed, and there was no tendency to further contraction.

The following are the cases previously alluded to in which uretbrotomy was performed (from notes by Mr. Apothecary Costello) :-

CASE 1.-Beeram Saib, Mahomedan, age thirty-five, ad. mitted to hospital 2nd April, 1880, with tight organic stricture of Jong standing. Urine can only be passed in drops with much straining, bladder greatly distended, and rupture threatening. No instrument can be passed through the stricture, which is situated in the subpubic region; and after all efforts at catheterism failed, the bladder was punctured per rectum, and a cannula and tube tied in. For some days subsequently trials were made to pass No. 1 catheter or bougie, but without success. On the 10th the conducting bougie of Mr. Teevan's urethrotome having been passed through the stricture with a little trouble, the staff was screwed on, and it was made to follow the bougie by means of moderate pressure into the bladder. The pressure was only necessary to get the thickened part, or point of junction between the bougie and staff, through the stricture, and that being passed, the shaft of the staff passed readily enough. The sheathed knife was now adjusted, and a small incision having been made at the meatus to allow it to pass, it was passed down to the stricture, and the blade being protruded this was thoroughly divided. To ascertain that this was done, the blade was retracted after resistance had ceased, and the sheath pushed further on, but no further obstruction being encountered the instrument was withdrawn, and a full rigid catheter passed. The man was discharged with a urethra of the full calibre on the 25th April, the rectal wound having healed. Mr. Teevan conditions that urine should flow through the groove in the staff before operation, but in this case it was not, as the bladder was kept empty by means of the cannula in the rectum. There was, however, no difficulty in satisfying oneself that the instrument was in the bladder, both because of the direction and of the facility with which its point moved about in the viscus, $\& c$. There was scarcely any bleeding from the operation.

CASE 2.-Buden Saib, Mahomedan, age fifty, admitted April 8th, 1880. Old-standing stricture; bus fistulous openings in perineum. No. 1 catheter passed after much difficulty. Was treated by catheterism in Shimoga two years ago, when urethra was dilated fully, but it began to contract soon after. Urethrotomy performed on April sth. very slight bleeding; No. 11 Englisb catheter passed readily afterwards. Fistulo closed; No. 12 catheter passes readily. Discharged April 18th, with a large instrument to pass oceasionally for himself.

CASE 3. - Bullaree, Hindu, age forty-five, admitted June 2nd, 1850, under Dr. P. H. Benson's care. Urine passing in drops; no catheter would pass; several fistulæ in perineum. Urethrotomy performed same day; no bleeding. Discharged with urethra of full calibre on June 20th, No. iz catheter passing easily, and fistulre closed. 
CASE 4. - J. W- European, age thirty, admitted under Dr. Benson's care on July 10th, 1880. Had been treated by gradual dilatation some time ago, but strictnre recurred, and urine passes now in a minute stream. Fistulous opening in perineum. No. 4 catheter a boule passed with difficulty. Catheter withdrawn afterwards, and there was so much difficulty in reintroducing it, that Mr. Teevan's instrument was used, and the stricture cut on the 13th. The strictured portion not having been completely divided, I used the urethrotome again on Aug. 1st, and after that there was no further difficulty. No. 12 English catheter passed freely, and the man was discharged on the 22nd, with a full-sized instrument given him to pass occasionally, the fistula having closed some time previously-viz., soon after the urethrotomy.

In the last case there was a little fever after the operation, but not more than followed catheterism previously, and it was readily controlled by quinine and opium. I also noticed that in No. 4 a well-curved catheter with a stilet in it, so as to direct its point along the roof of the urethra, passed more readily than a soft straight catheter or bougie aे boule, the explanation of which I assumed was, that the latter became engaged in the old fistulous orifice or annular portion of the stricture, whereas the former glided over or through the gap made by the knife, and which was ultimately filled up with the "cicatricial splice," which remained less prominent than the indurated part in the unincised portion.

Four cases are of course too few to draw any conclusions from, but if, according to the highest authorities, organic stricture is not curable, strictly speaking-i. e., the indurated structures giving rise to it are never completely removed, and the urethral canal restored to its original healthy state, and there is a liability to its recurrence, and if it is an "operation perfectly safe and easy to perform," then it would seem to me that internal urethrotomy is the operation for severe and obstinate cases, if not even for milder ones where, as in India, the surgeon may lack the necessary instruments occasionally, or the patients be unreasonable and disinclined to submit to lengthened treatment, and want to leave before the "gradual dilatation" process has more than half done its work. At all events I now feel myself, whether rightly or wrongly, that I can attack most cases of stricture and treat them efficiently by internal urethrotomy, without having the prospect of having to puncture the bladder before my eyes as previously whenever I failed with catheterism; that is, of course, wherever the filiform bougie of Mr. Teevan's instrument will pass, and the percentage of cases where it ought to fail is, I think, very small.

\section{THE CHLOROFORM DEATH-BILL FOR TWELVE MONTHS. ${ }^{1}$}

BY ERNEST H. JACOB, M.D.,

PHYSICIAN TO THE LEEDS DISPENSARY AND THE LEEDS FEVER HOSPITAL.

Is a previous communication ${ }^{2}$ I reviewed the great change that had occurred during the past few years in the substitution of ether for chloroform in surgical practice. In 1876 a return from the anæsthetists of the London and other large hospitals revealed the fact that, save for the aged and infants, ether had taken the place of chloroform in nearly all our great surgical centres, and not only this, but that the change was felt by the officers in charge of the administration to be one greatly to the advantage of the patients as regards their subsequent condition, as well as the mere aroidance of death while under the influence of the drug.

And yet, during the past twelve months, no less than twenty-tive deaths have occurred from chloroform-I ought rather to say, have been recorded, for, no doubt, many occur which it is convenient and possible to say nothing about. Of these twenty-five, seventeen only occurred in Great Britain, fifteen being in hospital, and eight in private practice. The operations were mostly of the simplest kind. Dressing wounded fingers or toes, three; necrosis, four; extraction of teeth, two; amputation of the breast and lithotrity, one

1 Read before the Leeds and West Riding Medico-Chirurgical Society.

2 On Ether as an Anæsthetic, THE LANCET, vol, ii. 1879, p. 539. each ; and one for applying a splint to a child's leg. The deaths appear to have occurred in the usual way from sudden syncope. As regards the post-mortem appearances, which are noted in fourteen cases, in five all organs were perfectly healthy. In eight only the heart was more or less "fatty" or "flabby," and in one there was emphysema of the lungs.

As regards locality, two deaths took place in the Edinburgh Infirmary, where, I believe, ether is not in use; two in the London Hospital, where ether is extensively used; and three in Liverpool.

During this period five deaths from other anæsthetics have been recorded. One each from ethydene dichloride and ethyl dibromide, and three from ether. Of the latter two occurred in America, one during extraction of teeth, no particulars being given, and one during an operation for hip disease, the patient suffering from valvular disease of the heart. The remaining case, the only one in England, was that recently reported by Mr. Hartley, which conld not be said to be due to the anæsthetic, as the patient was almost in articulo from intestinal obstruction when the operation was commenced.

It can hardly be too strongly urged that the fatality of an anæsthetic cannot be deduced from the experience of one observer. The cases must amount to tens of thousands. During the past few years, however, there has been no lack of material for statistical inquiry, and the result is to be read in the facts I have stated.

A death from an anæsthetic administered for a trivial operation cannot be regarded as anything but a serious calamity. It is not for me to say that a grave irresponsibility rests on the surgeon who employs chloroform when a safer anæsthetic is available, but I think it cannot be long before the voice of the profession (if not of the public, as in America) demands some explanation for the use of an agent whose victims are numbered by hundreds.

Leeds.

\section{IN TR O D UCTORY ADDRESS,}

Delivered at the Opening of the Winter Session of the School of Medicine, Surgeons' Hall, Edinburgh.

BY DR. FRANCIS W. MOINET.

GENTLEMEN,-It has devolved upon me in the name of your teachers to address to you this morning a few words of welcome and encouragement on the occasion of the commencement of the medical session. We welcome you as fellow students in a noble profession, which has for its aim the prevention and relief of human suffering, in striving to accomplish which you will find ample reward for all the labours of mind and body you may expend upon it. I take it for granted, gentlemen, you have chosen your profession thoughtfully for the love of it, because unless you feel your hearts are in the work you will neither do justice to yourselves nor to your work. It is one which should thoroughly commend itself to you in its aim and endeavours apart from all extrinsic questions as mere pecuniary reward. Now is the time to think of your work only, and how best you are to prepare yourselves for its responsible duties. In thinking over what I would address you upon this morning, it appeared to me that our time would be most profitably occupied in directing your attention briefly to what $\mathbf{I}$ consider is the right spirit in which you should prosecute your studies. This I feel can best be done by trying to impress upon you the importance of entertaining a high opinion of your profession and a clear idea of its responsibilities; the first will make you careful to do nothing to tarnish its reputation, and the second should stimulate you in your work, so that you will do credit to yourselves and to the profession for which you are now going to prepare yourselves, and so maintain if not raise the estimation in which it is held by the public, and increase its power of usefulness. In treating your patients you should be satisfied that you have used all the possible means which science and experience have gathered for our use. This is the responsibility which you undertake when you go out into the world to practise your profession, and which, if properly realised by you now, will be the best stimulus to you to worls hard as students, by 